\title{
THE COST OF EQUITY CAPITAL WITH PERSONAL INCOME TAXES AND FLOTATION COSTS
}

By

M.J. GORDON

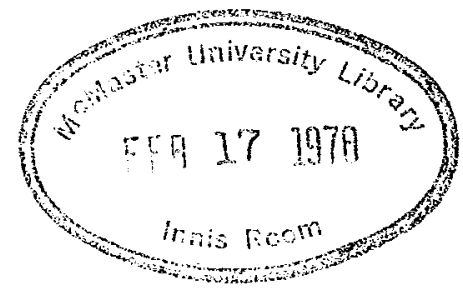

Professor of Finance

University of Toronto

and

\section{L.I. GOULD}

Assistant Professor of Finance McMaster University

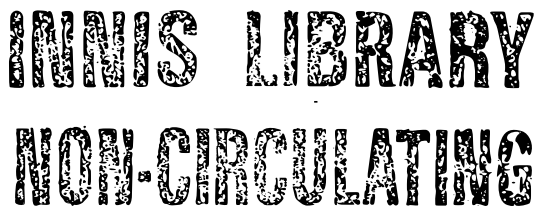

Innis

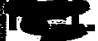

HB

74.5

.R47

Research and Working Paper Series No. 141

January, 1978

no.141 


\section{The Cost of Equity Capital with Personal Income Taxes}

and Flotation Costs

M.J. Gordon and L.I. Gould*

This paper establishes the cost of retention-financed capital and the cost of stock-financed capital.in the presence of personal income taxes and flotation costs under alternative theories of share valuation that are considered plausible.

In the absence of the tax and flotation costs (and information content to the dividend), the cost of equity capital is independent of its source. It then depends on whether a share's yield is independent of (SYI) or is dependent on (SYD) the firm.'s investment decision. It also depends on whether the return on investment functions in future periods are independent of (RIFI) or are dependent on (RIFD) the firm's current investment decision. Consequently, under the conditions stated there are four possible answers to the question, what is a corporation's cost of equity capital? Each of the pairs (1) SYI-RIFI, (2) SYD-RIFI, (3) SYI-RIFD, and (4) SYD-RIFD results in a different answer.

Part I reviews these four solutions to the cost of equity capital. Part II extends the four solutions to establish the costs of retention-financed and stock-financed capital in the presence of flotation costs and the differential tax treatment of dividends and capital gains. Part III compares the results obtained with the existing literature.

All that a search of the literature could find is the Lewellen [6] solution to the problem. That solution was confined to the SYI-RIFI case, and it assumed the pre-tax share yield is independent of the firm's investment decision.

* The authors are Professor of Finance, University of Toronto and Assistant Professor of Finance, HcMaster University, respectively. 
In fact, when the no-tax share yield is taken to be independent of the firm's investment decison, it is the after-tax share yield that takes on this property. The pre-tax share yield becomes a decreasing function of the dividend's rate of growth, and the Lewellen solution materially understates the costs of retention-financed and stock-financed capital under the SYI-RIFI assumptions.

I.

The cost of equity capital depends on whether the return on investment functions in future periods are dependent on (RIFD) or independent of (RIFI) the firm's current investment decisions. We will first examine the cost of equity capital models under each of these assumptions in the absence of personal taxes and flotation costs.

A. The RIFD Cost of Equity Capital Models

The implications for the cost of equity capital of the constant expected growth rate stock value model,

$$
P=(1-b) Y /(k-g)
$$

were examined in the early sixties by Gordon [3][4] and Lintner [7][8], and by Gordon and Gould [5] in a recent paper. In this equation:

$P=$ Present value of the firm's stock;

$Y=$ Expected value of the firm's earnings per share in the coming year;

$b=$ Expected value of the firm's retention rate, expressed as a fraction of eamings;

$g$ = Expected rate of growth in the dividend to a current share;

$k=$ Before-personal-tax required return or yield at which the stock is selling. 
Miller and Modigliani [10,p. 423] have shown that in the absence of personal taxes and transaction costs,

$$
g=[q r(1-b)-s k] /(1-q) \text {, }
$$

where the additional variables are defined as:

$s=$ Expected value of the firm's stock financing rate, expressed as a fraction of earnings;

$\mathrm{q}=$ Expected value of the firm's investment rate, expressed as a fraction of earnings $=b+s$;

$r=$ Expected value of the return on investment, with investment the fraction q of earnings.

Substituting this expression for $g$ in Eq. (1), and simplifying, results in

$$
P=(1-q) Y /(k-q r)
$$

If $r$ and $k$ are both functions of $q$, the partial derivative with respect to $\mathrm{q}$ is

$$
\frac{\partial P}{\partial q}=\frac{Y}{(k-q r)^{2}}\left\{-k+q r+(1-q) \operatorname{lr}+q\left(\frac{\partial r}{\partial q}\right)-\frac{\partial k}{\partial q} j\right\} .
$$

In the above $r^{\prime}=r+q(\partial r / \partial q)$ is the marginal rate of return on investment when investment is at the rate q. Setting Eq. (4) equal to zero and solving for $r^{\prime}$ we find that the value of $P$ is maximized when $q$ is set to satisfy

$$
r^{\prime}=(k-q r) /(1-q)+\partial k / \partial q
$$

The left hand side of Eq. (5), the marginal rate of return on investment, is a decreasing function of $q$, the firm's investment rate. 
The right hand side of Eq. (5) is also a function of $\mathrm{q}$, and it may be called the firm's cost of equity capital, since the value of $q$ that satisfies Eq. (5) maximizes share price. In other words, if the value of $r^{\prime}$ at some investment rate is above the right hand side of Eq. (5), undertaking the next most profitable investment will raise the value of the firm's stock and vice versa.

The term $(k-q r) /(1-q)$ reflects the assumption that the return on investment functions in future periods are dependent on the investment decision in a particular way. Hence, Eq. (5) with $\partial \mathrm{k} / \partial \mathrm{q}=0$ is the SYI-RIFD cost of equity capital, and with $\partial k / \partial q \frac{1}{\mathrm{~T}} 0$, we have the SYD-RIFD cost of equity capital.

On the rationale for the RIFD function reflected in $(k-q r) /(1-q)$, a recent paper by Elton and Gruber [1] investigated a wide range of assumptions with regard to a firm's future rate of return on investment functions, and derived the value of the firm and its cost of capital for each of these functions. For our purposes, the results of that paper may be sumarized as follows. First, if the return on investment function in each future period is independent of the firm's current investment decision, regardless of how these return on investment functions shift over time, a firm's cost of capital is $k$. That is, the firm's investment decision should equate the marginal rate of return on investment with the firm's share yield, assuming that $\partial k / \partial q=0$.

On the other hand, if the return on investment function in period $j$ depends in some way on the investment decision in period $t<j$, then regardless of what this relation is, a firm's cost of capital depends on its investment decision and is not equal to $k$, even if $k$ is independent of that investment decision. The expression $(k-q r) /(1-q)$ incorporates the 
particular assumption that the return on investment expressed as a function of $q$ in every future period is the same and independent of $q$, which means the return as a function of the level of investment shifts upward at a constant rate that increases with the value of qr. Arguments for and against this assumption may be found in Gordon and Gould [5] and Miller [9].

The theoretical basis for believing that the gield investors require on a share is an increasing function of the firm's investment rate $(\partial k / \partial q>0)$ is contained in Fewings [2]. An expression for share yield that incorporates this assumption in an empirically feasible manner is provided in Gordon [3] and Gordon and Gould [5].

\section{B. The RIFI Cost of Equity Capital Models}

In order to arrive at the cost of equity capital when the return on investment functions in future periods are independent of the current investment decisions, we define $\Delta$ to equal the rate of growth in price that is independent of the investment decision in the current period. The appropriate stock value model is

$$
\mathrm{P}=[\mathrm{Y}(1-\mathrm{b})+\mathrm{P}+\mathrm{P} \Delta+\mathrm{Y}(\mathrm{b}+\mathrm{s}) \mathrm{r} / \mathrm{k}-\mathrm{Y} s] /(1+\mathrm{k}) \text {. }
$$

The first term in the numerator is the dividend in the coming period. The next two terms are the recovery of the investment.in the stock, plus the appreciation in the stock due to investments the firm will make in subsequent periods, as well as other events that are independent of the firm's current decisions.

The next term is the price appreciation due to the current investment of $\mathrm{Y}(\mathrm{b}+\mathrm{s})$ to earn $r$. The last term is the value of the shares issued 
to cover the stock financed portion of the investment.

Rearranging Eq. (6) gives

$$
P=[Y(1-q+q r / k)] /(k-\Delta)
$$

Taking the partial derivative with respect to $q$, setting the result equal to zero, and solving for the marginal rate of return on investment results in

$$
\frac{\partial q r}{\partial q}=r^{\prime}=k+\frac{\partial k}{\partial q}\left[\frac{k(1-q)+q r}{k-\Delta}+\frac{q r}{k}\right]
$$

If $\partial k / \partial q=0$ we have the well known SYI-RIFI solution. The cost of equity capital is $k$. Without the assumption that $\partial k / \partial q=0, E q$. ( 8 ) is the SYD-RIFI solution to the cost of equity capital.

II.

This section will extend the previous models to recognize the presence of transaction costs and personal income taxes. With the debt ratio fixed, the corporate income tax may be ignored, and all that will concern us is the differential tax treatment of dividends and realized capital gains. The transaction costs of buying and selling outstanding shares is relatively small, and the only transaction costs that will be incorporated in the analysis are the flotation and under-pricing costs of a new issue.

The notation that will be employed beyond the terms introduced previously is: 
$t_{d}=$ Personal income tax rate on dividends;

$t_{g}=$ Personal income tax rate on realized capital gains;

$\mathbf{k}^{\tau}=$ Discount rate which equates the expected after-tax cash filows from a share with its price;

$\mathrm{w}=$ Flotation costs on a new issue expressed as a fraction of the funds raised from the issue, after adjusting for any corporate tax deductions;

$c_{s}=$ Cost of stock-financed capital;

$c_{b}=$ Cost of retention-financed capital.

In developing an after-tax model of stock value, we cannot assume as with Eq. (1) that the investor buys a stream of dividends for the infinite future. In that event, the investor would ignore the capital gains tax in putting a value on the share, and our tax problem would disappear. We assume that the investor plans on selling the share at the end of one period. As noted below in Part III, the extension of the model to the case where the investor plans on selling the share two or more periods hence only requires a reduction in the value of $\mathrm{t}_{\mathrm{g}}$. We also make the simplifying assumptions that all investors are subject to the same tax rate on dividends and the same tax rate on capital gains, and these two tax rates are not expected to change over time.

\section{A. The RIFD Assumption}

We first arrive at a model of stock valuation and cost of capital under the assumption that the firm's return on investment function in future periods is dependent on the current investment decision. As derived in the appendix, we can express the price of the firm's stock as 


$$
P=\frac{Y\left[(1-b)\left(1-t_{d}\right)-\left(1-t_{g}\right) s /(1-w)\right]}{k^{\tau}-\left(1-t_{g}\right)(b+s) r}
$$

subject to the usual convergence criterion, $k^{\tau}>\left(1-t_{g}\right)(b+s) r$, and a positive numerator.

If we set $t_{d}=t_{g}=w=0, E q$. (9) reduces to Eq. (3). However, with $t_{d} \neq t_{g}$ the one-period and infinite horizon models are different. To determine the cost of retention capital with no stock financing we set $s=0$ and take the derivative with respect to $b$.

$$
\frac{\partial P}{\partial b}=\frac{Y\left(1-t_{d}\right)}{\left[k^{\tau}-b r\left(1-t_{g}\right)\right]^{2}}\left\{\frac{\partial b I}{\partial b}(1-b)\left(1-t_{g}\right)-\frac{\partial k^{\tau}}{\partial b}(1-b)-k^{\tau}+b r\left(1-t_{g}\right)\right\} .
$$

Solving for the before-tax marginal rate of return on investment, we find that $P$ is maximized when $b$ is set to satisfy

$$
\frac{\partial b r}{\partial b}=r^{\prime}=q_{b}=\frac{k^{\tau}-\left(1-t_{g}\right) b r}{(1-b)\left(1-t_{g}\right)}+\frac{\partial k^{\tau} / \partial b}{1-t_{g}} \text {. }
$$

To obtain the cost of stock-financed capital with no retention financing, we set $b=0$ and take the derivative of $P$ with respect to $s$.

$$
\begin{gathered}
\frac{\partial P}{\partial s}=\frac{Y}{\left[k^{\tau}-s r\left(1-t_{g}\right)\right]^{2}}\left\{-\frac{1-t_{g}}{1-w}\left[k^{\tau}-\left(1-t_{g}\right) s r\right]-\left[\frac{\partial k^{\tau}}{\partial s}-\frac{\partial s r}{\partial s}\left(1-t_{g}\right)\right]\right. \\
\left.\left[1-t_{d}-s \frac{\left(1-t_{g}\right)}{(1-w)}\right]\right\} .
\end{gathered}
$$

Solving for $r^{\prime}$ once again we find that $P$ is maximized by the stock financing rate that satisfies

$$
\frac{\partial s r}{\partial s}=r^{\prime}=c_{s}=\frac{k^{\tau}-\left(1-t_{g}\right) s r}{\left(1-t_{d}\right)\left(1-r^{\prime}\right)-s\left(1-t_{g}\right)}+\frac{\partial k^{\tau} / \partial s}{1-t_{g}} \text {. }
$$


A comparison Jf Eqs. (11) and (13) reveals the difference between the costs of retention and stock-financed capital when the other is set equal to zero, for a given investment rate $q$ equal to $b$ or $s$. On the reasonable assumpt:-.on that $\partial \mathrm{k}^{\tau} / \partial \mathrm{b}=\partial \mathrm{k}^{\tau} / \partial s$, the two equations differ only in the denominators of the first tern. ${ }^{1}$ The denominator of Fq. (11) is larger by $t_{d}-t_{g}+w\left(1-t_{d}\right)$. It follows that the cost of stock-financed capital is larger due both to flotation costs and the difference between the tax rates on dividends and capital gains.

The conclusion that $c_{s}>c_{b}$ holds when the alternative source of funds is non-zero as well as when the altemative source of funds is zero. It follows that, with the investment rate constrained so that $b+s<1$, a firm will never engage in stock financing. This conclusion is contrary to fact. Some firms do on occasion engage in stock financing. Tro possible explanations are our assumption with regard to the dependence of the firm's investment function on prior investment decisions, and that the firm's dividend has no informational content:

\section{B. The RIFI Assumption}

We will see shortly that, with the firm's return on investment function independent of prior investment decisions, a firm may engage in stock financing. To establish the values of $c_{b}$ and $c_{s}$ for the RIFI case, we introduce personal income taxes and flotation costs to Eq. (6) to obtain

$$
\begin{gathered}
P=\left\{Y(1-b)\left(1-t_{d}\right)+P+P \Delta\left(1-t_{g}\right)+\left(1-t_{g}\right)\left[Y b r\left(1-t_{d}\right) / k^{\top}\right]\right. \\
\left.+\left(1-t_{g}\right) Y \frac{\operatorname{si}\left[1\left(1-t_{d}\right)-k^{\tau} /(1-w)\right]}{k^{\tau}}\right\} /\left(1+k^{\tau}\right) .
\end{gathered}
$$

$1_{\text {This represents }}$ the SYD-RIFD case, but in the SYI-RIFD case $\partial k^{\tau} / \partial b=\partial k^{\tau} / \partial s=0$, and the subsequent argument is unchanged. 
The first term is the after-tax dividend in the coming period. The next two terms are the tax-free recovery of the investment in the stock, plus the after-tax appreciation in the stock due to the investments the firm will make in subsequent periods, as well as other events that are independent of the firm's current decisions.

The next term is the after-tax capital gain due to the retention financed investment in the current period. This term assumes that the entire return on the investment will be paid out in dividends. In that event, the retention-financed investment will increase subsequent dividends by Ybr. Their after-tax periodic amount is $\operatorname{Ybr}\left(1-t_{d}\right)$. Dividing by $k^{\tau}$ produces their end-of-period present value, and multiplying by $\left(1-t_{g}\right)$ results in the after-tax capital gain. The last term is the endof-period after-tax capital gain due to the stock-financed investment during the period. The after-tax periodic income that accrues to the start-of-period shareholders is $\operatorname{Ysr}\left(1-t_{d}\right)$, less the outflow to new shareholders of $Y[s /(1-w)] k^{\tau}$. Here, also, the capital gain reflects the assumption that the return on the investment will be paid in dividends.

Valuing a firm's stock on the assumption that the future earnings on the current investment will all be paid in dividends may not be considered correct on the grounds that some part of these earnings will be retained and invested. Under this reasoning, Eq. (14) understates P, and the use of Eq. (14) to arrive at the cost of capital from each source would bias the figure upwards. However, the subsequent decision to retain any part of these earnings will depend on the after-tax profitability that these earning will finance. In other words, the tax advantage from retaining these eamings accrues to the future investments that will make their retention possible. It would then follow that with the no-tax return on investment 
function independent of prior investment decisions, the Eq. (14) treatment of the future earnings generated by current investment as being paid in dividends is correct. ${ }^{1}$

Solving Eq. (14) for $\mathrm{P}$ and taking the partial derivative with respect to $b$ gives:

$$
\frac{\partial P}{\partial b}=\frac{Y\left(1-t_{d}\right)}{\left[k^{\tau}-\Delta\left(1-t_{g}\right)\right]^{2}}\left[\begin{array}{c}
{\left[k^{\tau}-\Delta\left(1-t_{g}\right)\right]\left[-1+\left[\left[k^{\tau}\left(1-t_{g}\right) \frac{\partial b r}{\partial b}\right]-\left[\left(1-t_{g}\right) b r\right] \frac{\partial k^{\tau}}{\partial b}\right\}\right.} \\
k^{\tau 2} \\
-\left[(1-b)+\frac{\left(1-t_{g}\right) b r}{\left.k^{\tau}\right] \frac{\partial k^{\tau}}{\partial b}}\right.
\end{array}\right] \text {. }
$$

Solving for the marginal rate of return on investment, we find that the value of $b$ which satisfies

$$
\frac{\partial b r}{\partial b}=r^{\prime}=c_{b}=\frac{k^{\tau}}{1-t_{g}}+\frac{\partial k^{\tau}}{\partial b}\left\{\frac{k^{\tau}(1-b)+\left(1-t_{g}\right) b r}{\left[k^{\tau}-\Delta\left(1-t_{g}\right)\right]\left(1-t_{\dot{g}}\right)}+\frac{b r}{k^{\tau}}\right\}
$$

maximizes the stock price.

Setting $b=0$, and carrying out the analogous operations for the stock financing decision, we find that

$$
\frac{\partial s r}{\partial s}=r^{\prime} \because c_{s}=\frac{k^{\tau}}{\left(1-t_{d}\right)(1-w)}+\frac{\partial k^{\tau}}{\partial s}\left\{\frac{k^{\tau}\left[1-\frac{s\left(1-t_{g}\right)}{\left(1-t_{d}\right)(1-w)}\right]+\left(1-t_{g}\right) s r}{\left[k^{\tau}-\Delta\left(1-t_{g}\right)\right]\left(1-t_{g}\right)}+\frac{s r}{k^{\tau}}\right\} .
$$

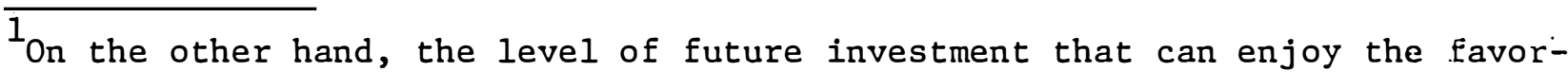
able tax treatment of retention financing depends on the level of future earnings, which in turn depends on the level of current investment, retention or stock-financed. Hence, even when the no-tax return on investment function is independent of prior investment decisions, the differential tax treatment of dividends and capital gains creates dependence. We assume that this dependence is small and can be ignored.
} 
Comparison of the two cost of capital expressions supports the conclusion that $c_{s}>c_{b}$. The denominator of the first term for $c_{b}$, which is $1-t_{g}$, exceeds the corresponding term in $c_{s}$ by $t_{d^{-}} t_{g}+w\left(1-t_{d}\right)$. This is the same difference that we had in Eqs. (11): and (13). The second term on the right hand side of Eq. (17) is greater than the corresponding term in Eq. (16) since $b<s\left(1-t_{g}\right) /\left(1-t_{d}\right)(1-w)$. However, the contribution of these terms to the excess of $c_{s}$ over $c_{b}$ is likely to be sma.l l, because we are only changing the levels of the current retention and stock financing rates, and $k^{\top}$ varies with the long run rate of growth. Furthermore, these terms disappear in the SYI-RIFI case where $\partial k^{\tau} / \partial b=\partial k^{\tau} / \partial s=0$.

It does not follow that the firm will never engage in stock financing, for now the investment decision is not constrained so that b+s $<1$. With a firm's return un investment function dependent on prior investment decisions, $\mathrm{q}=\mathrm{b}+\mathrm{s}$ is the firm's long run investment rate, and a firm with $\mathrm{q}>1$ under these conditions is a sink. However, with the return on investment function independent of prior investment decisions, q may vary in any way from one period to the next, and $q>1$ in any period does not imply that the firm is a net drain on society.

With $c_{b}<c_{s}$ the firm would use retention financing as long as $r^{\prime}$ remained greater than the right hand side of Eq. (16). However, the use of retention financing for investment is subject to a constraint. At a maximum $b=1$, and if the dividend contains information with regard to future dividends and earnings, a firm may well constrain $b<1$. If the constrained value of $\mathrm{b}$ does not satisfy Eq. (16), then stock financing is not precluded. We can take the partial derivative of Eq. (14) with respect to $s$, treating the constrained value of $b$ as a constant, and solve for the marginal return on investment to obtain 
$\frac{\partial q r}{\partial q}=\frac{\partial q r}{\partial s}=r^{\prime}=c_{s}=\frac{k^{\tau}}{\left(1-t_{d}\right)(1-w)}+\frac{\partial k^{\tau}}{\partial s}\left\{\frac{k^{\tau}\left[1-b-\frac{s\left(1-t_{g}\right)}{\left(1-t_{d}\right)(1-v)}\right]+\left(1-t_{g}\right) q r}{\left[k^{\tau}-\Delta\left(1-t_{g}\right)\right]\left(1-t_{g}\right)}+\frac{q r}{k^{\tau}}\right\}$.

Finally, in comparing Eqs. (11) and (13) with Eqs. (16) and (17), it is not possible to make any simple statements with regard to how the cost of each source of funds differs depending on the properties of the firm's return on investment function. Nonetheless, it would seem that the optimal investment is higher with the return on investment function inderendent of prior investment decisions than under the alternative assumption.

III.

As stated earlier Lewellen [6] contains the only previous solution to the problem that was turned up by our search of the literature. ${ }^{1}$ He posed the following question for a firm that is initially paying out all of its earnings in dividends: if an investment of by is made, and all

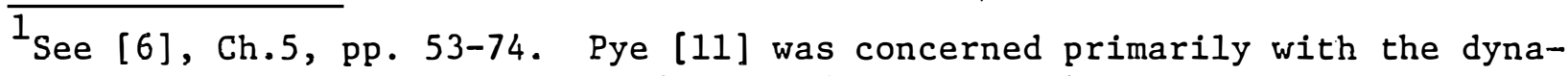
mic choice between retention and stock financing, that is, the extent to which a firm should retain earnings in order to avoid stock financing in subsequent periods. He arrived at the same conclusions with regard to the cost of capital as Lewellen.

- Solomon [12] argued that the cost of equity capital with the differential tax treatment of dividends and capital gains is simply $k$ on the reasoning that firms may invest in the shares of other firms to earn $k$ without limit and thereby avoid paying any dividends. There is some merit in Solomon's solution insofar as firms are free to repurchase their own shares. If the tax authorities allow firm's to label dividends as share repurchases, the cost of equity capital from each source is as presented below with $t_{d}=0$. 
subsequent earnings from this investment are paid out in dividends, what rate of return will leave the stockholder indifferent to receiving by in dividends? If bY is paid in dividends the investor will receive bY( $\left.1-t_{d}\right)$ after taxes. Alternatively, he argued, the retention of by will provide a perpetual stream of earnings of bYr', which when discounted at $k$ results in an after-tax capital gain of (bYr'/k)(1-tg). Equating the two wealth levels gives

$$
b Y\left(1-t_{d}\right)=\left(b Y r^{\prime} / k\right)\left(1-t_{g}\right)
$$

Solving for the required return on investment, Lewellen found that the cost of retention capital is

$$
r^{\prime}=c_{b}=k\left(1-t_{d}\right) /\left(1-t_{g}\right)
$$

In reaching this solution Lewellen implicitly assumed that both $\mathrm{k}$ and the return on investment functions in future periods are independent of the current investment decision. Hence, our SYI-RIFI model, which incorporates the same assumptions, is comparable to the Lewellen model. Our solution in that case was Eq. (16) with $\partial \mathrm{k} / \partial \mathrm{b}=0$ or

$$
r^{\prime}=c_{b}=k^{\tau} /\left(1-t_{g}\right)
$$

Comparison of Eqs. (19) and (20) raises two questions. Is $k^{\tau}=k\left(1-t_{d}\right)$ ? In that case our solution is the same as Lewellen's. If $k^{\tau} \neq k\left(1-t_{d}\right)$ which solution is right? The relation between $k$ and $k^{\tau}$ can be established by noting that the price of a share can be expressed in terms of either before-tax or after-tax cash flows, as long as the appropriate discount rate is used. That is, with $D$ the next period's expected dividend, and $g$ the expected growth in price, we have 


$$
P=[D+P(1+g)] /(1+k)=D /(k-g)
$$

or

$$
\begin{aligned}
P & =\left[D\left(1-t_{d}\right)+P(1+g)-t_{g}[P(1+g)-P]\right\} /\left(1 \div k^{\tau}\right) \\
& =D\left(1-t_{d}\right) /\left[k^{\tau}-g\left(1-t_{g}\right)\right] .
\end{aligned}
$$

With $P$ the same in both equations, we may equate the two expressions for $P$ and solve for $k^{\tau}$. The result is

$$
k^{\tau}=k\left(1-t_{d}\right)+\ddot{g}\left(t_{d}-t_{g}\right)
$$

Solving for $k$, we obtain

$$
k=\frac{k^{\tau}}{1-t_{d}}-\frac{g\left(t_{d}-t_{g}\right)}{1-t_{d}} .
$$

It is clear then that $k^{\tau}=k\left(1-t_{d}\right)$ only in the uninteresting special case where $g=0$. Furthermore, as $g$ and $t_{d}^{-t} g$ increase, the difference between $k$ and $k^{\tau} d e-$ creases.

The determination as to whether Eq. (19) or (20) is the correct expression for the cost of retention capital under the SYI-RIFI assumptions is facilitated by deriving our Eq. (20) under the Lewellen mode of analysis. The investment of bY generates a periodic Euture dividend or bYr', but the future dividends that an investor receives is net of taxes, or $\left(1-t_{d}\right) b Y r^{\prime}$. Hence, the price appreciation that results is $\left(1-t_{d}\right) b Y r^{\prime} / k^{\top}$ and not bYr'/k. It is as simple as that. Consequently, the correct equality between tie wealth levels represented by paying bY in dividends and investing j? is

$$
\dot{D Y}\left(1-t_{d}\right)=\left(1-t_{d}\right)\left(b Y r^{\prime} / k^{\tau}\right)\left(1-t_{g}\right)
$$

Solving this expression for $r^{\prime}=c_{b}$ results in our Eq. (20). 
Comparison of what had been considered and what we now see is the corract solution for the SYI-RIFI cost of retention capital is facilitated. by substituting Eq. (23) for $k^{\tau}$ in Eq. (20). . The result is

$$
r^{\prime}=c_{b}=\frac{k\left(1-t_{d}\right)}{1-t_{g}}+\frac{g\left(t_{d}-t_{g}\right)}{1-t_{g}} .
$$

We see that $c_{b}$ exceeds the Lewellen solution by an amount that varies with the share's expectad rate of growth and with $t_{d^{-t}} t$. A simple numerical illustration provides some indication of the quantitative inportance of the correction. Assume a share with $k=.13, g=.07, t_{d}=.50$ and $t_{g}=.25$. The Lewellen solution is $c_{b}=.0867$ and our solution is $c_{b}=.1100$.

For the cost of stock-financed capital Lewellen recommended $c_{s}=k /(i-w)$. Our solution under the SYI-RIFI assumptions is Eq. (17) with $\partial k^{\top} / \partial s=0$ or

$$
r^{\prime}=c_{s}=k^{T} /\left(1-t_{d}\right)(1-w)
$$

Substituting for $k^{\top}$ results in

$$
r^{\prime}=c_{s}=\frac{k}{1-w}+\frac{g\left(t_{d}-t_{g}\right)}{\left(1-t_{d}\right)(1-w)} .
$$

Again rie see that Lewellen's rasult is obtained only with $g=0$, and the error increases with $g$ and with $t_{d^{-t}} g^{\cdot}$

The following observations may be of some nelp in interpreting and using our SYI-RIFI models for the costs of retention and stock-Einanced capital. We start with the generally accepted proposition that investors usa after-tax cash Flows in arriving at an asset's value. Eence, the SII assumption in tize absence of tases implies that with a personal income tax it is $k^{T}$ and not $k$ that takes on this independence property. Accordingly, Eq. (20) and not Eq. (19) is the correct measure of the cost of zetenticn capital. 
However, we cannot observe $k^{\tau}$ directly, while we can observe $k$. Accordingly, given $g, t_{d}$ and $t_{g}$ as well as $k$, we may make the substitution that results in tqs. (26) and (28) Eor $c_{b}$ and $c_{s}$. Assume now that a change in $z$ is contemplated for a firm. We cannot use the old $k$ and the ner $g$ to arrive at

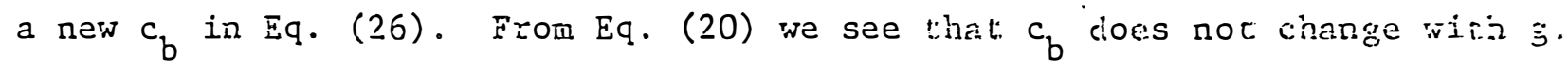
The old $k$ and $g$ way be used with Eq. (23) to arrive at $k^{\top}$. Eq. (24) may then be used to arrive at the change in $k$ with $g$.

In using Eq. (23) to arrive at $k^{r}$ or in using Eq. (25) to arrive ar $c_{b}$ directly, we require $t_{d}$ and $t_{g}$ as well as $k$ and $g$. A resonable figure for $t_{d}$ is a weighted average of the marginal tax rates on ordinary income with the rieignts based on the taxpayers relative holdings of shares. IE the capital gains tax rate is $25 \%$ or half the ordinary tax rate, these figures should be used if investors hold shares for one period. The longar the average holding period for shares, the lower the effective tax rate on capital gains. In the limit if all investors hold all shares îrever, "I goes to zero. $1 /$

\footnotetext{
See rihaley [1.3] For the determination of how the effective capical zaizs $53 x$ rate declines with the holding period and an estimate oi the eifective zata.
} 


\section{Appendix}

The additfonal symbols which will be used in this appendix are defined below:

$V_{t}=$ Value oĩ the firm at the end of period $t$;

$x_{t}=$ Expected value of the firm's earnings in period $t$;

$\mathrm{n}=$ Number $0 \tilde{\mathrm{I}}$ shares currently outstandizg at $\mathrm{t}=0$;

We can express the cuirent value of the firg, $v_{0}$, as

$$
\begin{gathered}
v_{0}=\frac{x_{1}(1-b)\left(1-t_{d}\right)}{1+k^{\tau}}+\frac{\left[V_{1}-\frac{s}{1-w} x_{1}\right]}{1+k^{\tau}} \\
-\frac{t_{g}\left[\left[V_{1}-\frac{s}{1-r_{j}} x_{1}\right]-V_{0}\right\}}{1+k^{\tau}} .
\end{gathered}
$$

The first ter on the right hand side is the discounted value of the after-tax dividend. The second term is the discounted value of the investors' holdings after any retention or nes stocle financing, which are assumed to occur at the end of the period. Notice that the firm must sell $\left(\frac{s}{1-w}\right) X_{1}$ stock in order to provide new equity capital of $s x_{1}$ after flotation costs. The third term is the discounted capital gains tax.

$$
\text { Now, letting } D=\left[(1-b)\left(1-t_{d}\right)-\frac{s}{1-w}\left(1-t_{g}\right)\right] \text {, we can rearrange }
$$

Eq. (A1) to give

$$
v_{0}=\frac{x_{1} D}{1+k^{\tau}-t_{g}}+\left(\frac{\left(1-t_{g}\right)}{1-k^{\tau}-t_{g}}\right)\left(v_{1}\right)
$$

In the following period, earnings will grow due to retention financing by $b x_{1} r$ and due to stock financing by $s x_{1}=$, and we have

$$
x_{2}=x_{1}+b x_{1} r+s x_{1} r=x_{1}(1+b r+s r)
$$


and generalizing:

$$
x_{t+1}=x_{1}(1+b r+s r)^{t}
$$

We can therefore expiress $V_{1}$ as

$$
v_{1}=\frac{x_{1}(1+b r+s r) \emptyset}{1+k^{\tau}-t_{g}}+\frac{\left(1-t_{g}\right)}{1+k^{\tau}-t_{g}} v_{2},
$$

and generalizing:

$$
v_{t}=\frac{x_{1}(1+b r+s r)^{t} \emptyset}{1+k^{\tau}-t_{g}}+\frac{\left(1-t_{g}\right)}{1+k^{\tau}-t_{g}} v_{t+1} .
$$

Substituting Eq. (A4) into Eq. (A2) gives

$$
\begin{aligned}
v_{0}= & \frac{x_{1} \emptyset}{1+k^{\tau}-t_{g}}+\left[\frac{1-t_{g}}{1+k^{\tau}-t_{g}}\right]\left[\frac{x_{1}(1+b r+s r) \emptyset}{1+k^{\tau}-t_{g}}\right]+ \\
& {\left[\frac{1-t_{g}}{1+k^{\tau}-t_{g}}\right]^{2}\left[\frac{x_{1}(1+b r+s r)^{2} \emptyset}{1+k^{\tau}-t_{g}}\right]+\ldots }
\end{aligned}
$$

Therefore,

$$
v_{0}=\left(\frac{x_{1} \emptyset}{1+k^{\tau}-t_{g}}\right)\left(\sum_{t=0}^{\infty} \frac{\left[(1+b r+s r)\left(1-t_{g}\right)\right]^{t}}{\left[1+k^{\tau}-t_{g}\right]^{t}}\right)
$$

Evaluating the infinite sum and substituting the definition of $\emptyset$ results in

$$
V_{0}=\frac{x_{1}\left[(1-b)\left(1-t_{d}\right)-\left(\frac{s}{1-w}\right)\left(1-t_{g}\right)\right]}{k^{\tau}-(b+s) r\left(1-t_{g}\right)}
$$

if $\quad k^{\tau}>(b+s) r\left(1-t_{g}\right)$.

Since $\mathrm{V}_{0}=\mathrm{nP}{ }_{0}$, and $\mathrm{x}_{1}=\mathrm{nY}$, we can also express Eq. (AS) on a per-share basis. Dividing both sides by $\mathrm{n}$ results in Eq. ( 9 ) in the text. 


\section{REFERENCES}

1. Elton, E.J. and Gruber, M.J. "Valuation and Asset Selection Under Alternative Investment Opportunities," Journal of Finance 3]. (May, 1976): 515-39.

2. Fewings, D.R. "The Impact of Corporate Growth on the Risk of: Common Stocks," Journal of Finance 30 (May 1975): 525-31.'

3. Gordon, M.J. The Investment, Financing, and Valuation of the Corporation. Homewood, Ill.: Richard D. Irwin, 1962.

4. "The Savings, Investment, and Valuation of the Corporation," Review of Economics and Statistics. 44 (February, 1962): $37-49$.

5. Gordon, M.J. and Gould, L.I. "The Cost of Equity Capital: A Reconsideration," Journal of Finance, forthcoming.

6. Lewellen, W.G. The Cost of Capital. Belmont, California: Wadsworth, 1969 .

7. Lintner, J. "The Cost of Capital and Optimal Financing of Corporate Growth," Journal of Finance 30 (May 1963): 292-310.

8. . "Optimal Dividends and Corporate Growth Under Uncertainty," The Quarterly Journal of Economics 78 (February 1964): 49-95.

9. Miller, M.H. "Discussion," Journal of Finance 30 (May 1963): 525-31.

10. Miller, M.H. and Modigliani, F. "Dividend Policy, Growth, and the Valuation of Shres," Journal of Business. 34 (October 1961): 411-33.

11. Pye, G. "Preferential Tax Treatment of Capital Gains, Optimal Dividend Policy, and Capital Budgeting," Journal of Political Economy, (May, 1972): 226-42.

12. Solomon, E. The Theory of Financial Management. New York: Columbia University Press, 1963.

13. Whaley, Robert "The Personal Income Tax in the CAPM," Working Paper, Faculty of Management Studies, University of Toronto, 1977. 
Faculty of Business

McMaster University.

WORKING PAPER SERIES

101. Torrance, George W., "A Generalized Cost-effectiveness Model for the Evaluation of Health Programs," November, 1970.

102. Isbester, A. Fraser and Sandra C. Castle, "Teachers and Collective Bargaining in Ontario: A Means to What End?" November, 1971.

103. Thomas, Arthur L., "Transfer Prices of the Multinational Firm: When Will They be Arbitrary?" (Reprinted from: Abacus, Vol. 7, No. 1, June, 1971).

104. Szendrovits, Andrew Z., "An Economic Production Quantity Model with Holding Time and Costs of Work-in-process Inventory," March, 1974.

111. Basu, S., "Investment Performance of Common Stocks in Relation to their Price-earnings Ratios: A Text of the Efficient Market Hypothesis," March, 1975.

112. Truscott, William G., "Some Dynamic Extensions of a Discrete LocationAllocation Problem," March, 1976.

113. Basu, S. and J.R. Hanna, "Accounting for Changes in the General Purchasing Power of Money: The Impact on Financial Statements of Canadian Corporations for the Period 1967-74," April, 1976. (Reprinted from Cost and Management, January-February, 1976).

114. Deal, K.R., "Verification of the Theoretical Consistency of a Differential Game in Advertising," March, 1976.

114a. Deal, K.R. "Optimizing Advertising Expenditures in a Dynamic Duopoly," March, 1976.

115. Adams, Roy J., "The Canada-United States Labour Link Under Stress," [1976].

116. Thomas, Arthur L., "The Extended Approach to Joint-Cost Allocation: Relaxation of Simplifying Assumptions," June, 1976.

117. Adams, Roy J. and C.H. Rummel, "Worker's Participation in Management in West Germany: Impact on the Work, the Enterprise and the Trade Unions," September, 1976.

118. Szendrovits, Andrew Z., "A Comment on 'Optimal and System Myopic Policies for Multi-echelon Production/Inventory Assembly Systems'," [1976].

119. Meadows, Ian S.G., "Organic Structure and Innovation in Small Work Groups," October, 1976. 
120. Basu, S., "The Effect of Earnings Yield on Assessments of the Association Between Annual Accounting Income Numbers and Security Prices," October, 1976.

121. Agarwal, Naresh C., "Labour Supply Behaviour of Married Women - A Mode1 with Permanent and Transitory Variables," October, 1976.

122. Meadows, Ian S.G., "Organic Structure, Satisfaction and Personality," October, 1976.

123. Banting, Peter M., "Customer Service in Industrial Marketing: A Comparative Study," October, 1976. (Reprinted from: European Journal of Marketing, Vo1. 10, No. 3, Summer, 1976).

124. Aivazian, V., "On the Comparative-Statics of Asset Demand," August, 1976.

125. Aivazian, V., "Contamination by Risk Reconsidered," October, 1976.

126. Szendrovits, Andrew Z. and George 0. Wesolowsky, "Variation in. Optimizing Serial Multi-Stage Production/Inventory Systems, March 1977.

12]. Agarwal, Naresh C., "Size-Structure Relationship: A Further Elaboration," March 1977.

128. Jain, Harish C., "Minority Workers, the Structure of Labour Markets and Anti-Discrimination Legislation," March, 1977.

129. Adams, Roy J., "Employer Solidarity," March, 1977.

130. Gould, Lawrence I. and Stanley N. Laiken, "The Effect of Income Taxation and Investment Priorities: The RRSP;" March 1977.

131. Callen, Jeffrey L., "Financial Cost Allocations: A Game-Theoretic Approach," March 1977.

132. Jain, Harish C., "Race and Sex Discrimination Legislation in North America and Britain: Some Lessons for Canada," May, 1977.

133. Hayashi, Kịchiro. "Corporate Planning Practices in Japanese Multinationals. Accepted for publication in the Academy of Management Journa1 in 1978.

134. Jain, Harish C., Neil Hood and Steve Young, "Cross-Cultural Aspects of Personnel Policies in Multi-Nationals: A Case Study of Chrysler UK", June, 1977.

135. Aivazian, V. and J. L. Callen, "Investment, Market Structure and the Cost of Capital", July, 1977. 
136. Adams, R. J., "Canadian Industrial Relations and the German Example", October, 1977.

137. Callen, J. L., "Production, Efficiency and Welfare in the U.S. Natural Gas Transmission Industry", October, 1977.

138. Richardson, A. W., "Cost-Volume-Profit Analysis and the Value of Information", November, 1977.

139. Jain, Harish C., "Labour Market Problems of Native People in Ontario", December, 1977.

140. Gordon, M.J. and L.I. Gould, "The Cost of Equity Capital: A Reconsideration", January, 1978. 
Innis

74.5

- R47 no. 141 